\title{
Staying Connected to Hospice Patients
}

\author{
G. Gayle Stephens, MD
}

When I was assigned to review the article that is published in this issue ${ }^{1}$ I was still ruminating about the hospice deaths of family members of two of my friends-one I had observed and the other told to me. In both instances there were questions about the appropriateness and timeliness of the referral to hospice and how facts other than the clinical conditions of the patients might have affected the process.

In one instance referral occurred abruptly at the end of a family conference with physicians in the patient's hospital room. When the patient chose not to undergo recommended palliative surgery for cancer of the colon, the unexpected response to that choice was same-day dismissal of the patient to her home. The family objected and asked about referral to hospice, which was agreed to but not conducted in a timely manner by the family physician. Hospice as an afterthought to a refusal.

What this instance lacked in foresight and planning, the second exceeded in efficiency. A man, able to return home by commercial airline after an episode of chest pain while traveling for pleasure, was referred to home hospice care after 2 weeks of cardiac care in the hospital. The diagnosis was intractable congestive heart failure, and he died 7 days later. What I observed in visiting the patient in the hospital and at home was lingering doubt about whether all medical options had been exhausted. One consultant suggested the possibility of an electrophysiological intervention, but the conditions of accepting hospice care precluded seeking that option after discharge from the hospital. Hospice as a routine item on a discharge checklist.

These two sets of events, both of which were more complex than can be accommodated in this format, provoked my reading at Medicare Web sites and discussions with colleagues. They were the backdrop for my first reading of this article. I

Submitted 10 January 2003.

Address reprint requests to G. Gayle Stephens, MD, 4300 Overlook Road, Birmingham, AL 35222. was delighted by the writer's genuine interest in the patient, his willingness to grapple with her problems, and his capacity for self-disclosure, and I was bemused by the audacity that innocence allows. Even so, I felt critical of assigning a student to such a difficult clinical encounter without apparent preparation and support and dismissive toward surgeons who were unable to persuade a patient with acute appendicitis to have surgery promptly.

What worried me was this: Since hospice has become a mainstream option, who is looking after the patients? Our medical student observed, somewhat wryly, I thought, that "... her physician did not seem to be a source of support. ..." Not only that, a physician rejected the plan for drainage of the abscess that the student negotiated with the patient. Was there a tinge of recrimination in that rejection?

It seems easy enough for physicians to refer patients, but what happens after that? I am told that each hospice has a medical director, and that the patient's personal physician may elect to continue care, but I wonder how that actually works out in most cases. Neither of the patients cited above continued to receive care from the physicians who referred them to hospice. On the other hand, I know a rural family physician who insists on continuity of care and has reached an accommodation with the local hospice, but not without some conflicts. What does it mean to be medical director of a community-based hospice? Is this mainly an administrative or a clinical job?

Hospice has finessed the dilemmas of quandary ethics that exercised institutional medicine and the courts so much in the 1970s and 1980s and made Karen Quinlan and Nancy Cruzan well known in the annals of case law. The state now appears willing not to press its claim to protect life under all circumstances, and mercifully, one can die at home without someone having to call the police or even the coroner-if one is in hospice. Pain and suffering can be relieved, even though such treatment might shorten life, so long as causing death is not 
intended. It is a fine distinction, a legal fiction worthy of sophists and scholastics in any age. I congratulate us that we find it useful.

But a holy and peaceful death was not Mrs. Smith's main goal. Like the poet Edna St. Vincent Millay, she was "not resigned to the shutting away of loving hearts in the hard ground." ${ }^{2}$ She wanted relief and to "enjoy whatever time she had left." Clearly, she was not an appropriate candidate for hospice care, and her nurse was expecting her to be discharged. I hope she got herself a new set of physicians who were interested in and respectful of whatever she chose about her medical care. The medical student's instincts to reevaluate, understand, negotiate, and advocate were right and are almost never inappropriate in doctoring of any sort.
What I am advocating here is that family physicians, especially, cultivate a bias to continue to care for their patients who are in hospice. If it is not possible on a formal basis, they should find some way to maintain informed social contact. We all will lose a piece of moral credibility if we arrange things so that we never have to see our patients die.

\section{References}

1. Baker BL, Joyce JM. Medical student reflects on hospice experience. J Am Board Fam Pract 2003;16: 262-4.

2. Millay E St V. Dirge without music. In: The buck in the snow and other poems. New York: Harper \& Row, 1952. 